\title{
Emergence of oriental theileriosis in cattle and its transmission through Rhipicephalus (Boophilus) microplus in Assam, India
}

Parikshit Kakati ${ }^{1}$, Prabhat Chandra Sarmah ${ }^{1}$, Debdatta Ray ${ }^{2}$, Kanta Bhattacharjee ${ }^{1}$, Rajeev Kumar Sharma ${ }^{3}$ Luit Moni Barkalita4, Dipak Kumar Sarma ${ }^{5}$, Bhaben Chandra Baishya ${ }^{5}$ Pranjal Borah ${ }^{6}$, and Bobitha Stanley ${ }^{2}$

1. Department of Parasitology, College of Veterinary Science, Assam Agricultural University, Guwahati, Assam, India; 2. Division of Parasitology, Indian Veterinary Research Institute, Izatnagar, Uttar Pradesh, India; 3. Department of Microbiology, College of Veterinary Science, Assam Agricultural University, Assam, India; 4. Department of Animal Biotechnology, College of Veterinary Science, Assam Agricultural University, Assam, India; 5. Teaching Veterinary Clinical Complex, College of Veterinary Science, Assam Agricultural University, Assam, India; 6. Goat Research Station, Burnihat, Assam Agricultural University, Assam, India.

Corresponding author: Kanta Bhattacharjee, e-mail: kantabhatta@gmail.com, PK: parik67@gmail.com, PCS: pcsarmah@gmail.com, DR: dd_rayvet@yahoo.co.in, RKS: dr.sharmark@rediffmail.com, LMB: luitbarkalita@gmail.com, DKS: drdipak77@gmail.com, BCB: bhabenchbaishya@gmail.com, PB: drpran2002@yahoo.co.in, BS: bobitha916@gmail.com Received: 01-06-2015, Revised: 12-08-2015, Accepted: 20-08-2015, Published online: 22-09-2015

doi: 10.14202/vetworld.2015.1099-1104 How to cite this article: Kakati P, Sarmah PC, Ray D, Bhattacharjee K, Sharma RK, Barkalita LM, Sarma DK, Baishya BC, Borah P, Stanley B (2015) Emergence of oriental theileriosis in cattle and its transmission through Rhipicephalus (Boophilus) microplus in Assam, India, Veterinary World 8(9): 1099-1104.

\begin{abstract}
Aim: The aim of the present study was to investigate the presence of Theileria in blood samples of crossbred and indigenous adult cows raised under unorganized small scale farming system in a Babesia and Anaplasma endemic geographical area from Assam, India and to see its transmission through Rhipicephalus (Boophilus) microplus ticks.

Materials and Methods: For the present study, 57 clinical cases of cattle suspected to be of hemoparasitic infections were taken into consideration. The parasites were identified based on morphology in giemsa stained blood smear followed by polymerase chain reaction (PCR). Sera samples were tested for T. annulata antibodies in plate and Dot-ELISA. PCR was also conducted in eggs of Rhipicephalus (Boophilus) microplus tick collected from a Theileria orientalis positive animal.

Results: PCR amplified 1124, 776, and 160 bp DNA fragments of B. bigemina (64.91\%),T. orientalis(21.05\%) and A. marginale $(14.03 \%)$, respectively. This assay further conducted in 12 T. orientalis positive blood samples with primers of Buffeli, Chitose, and Ikeda variants of T. orientalis showed 3 samples positive to Ikeda type and none for Buffeli and Chitose. Babesia bovis and Theileria annulata specific primers also did not amplify any fragment during the PCR assay of the blood samples. Further, all sera samples tested negative to T. annulata antibodies in Plate and Dot-ELISA. PCR conducted in eggs of $R(B)$.microplus tick collected from a T. orientalis positive animal revealed presence of the parasite DNA. Gradual improvement in physical condition leading to complete recovery in 10 out of 12 T. orientalis infected clinical cases treated with buparvaquone(at $2.5 \mathrm{mg} / \mathrm{kg}$.b.wt I/M) was the feedback obtained from field veterinarians and the cattle owners.
\end{abstract}

Conclusion: The present investigation represents the first report of occurrence of $T$. orientalis in cattle of Assam with involvement of pathogenic Ikeda strain in clinical outbreaks and its possible natural transmission by $R$ (B). microplus through the transovarian mode.

Keywords: Anaplasma marginale, Assam (India), Babesia bigemina, Ikeda type, Rhipicephalus (Boophilus) microplus, Theileria orientalis.

\section{Introduction}

Theileria orientalis, a hemoprotozoan parasite of cattle and the causative agent of oriental theileriosis in the Asian countries in former times has now been reported from different countries in the tropics and sub-tropics. It is believed to be transmitted transtadially through different species of Haemaphysalis ticks $[1,2]$. The parasite was previously considered non-pathogenic since it caused mild anemia in cattle of endemic areas [2]. However, in the recent past the parasite has emerged pathogenic as evidenced by a number of clinical outbreaks characterized by fever, anemia, jaundice and abortion and even mortality

Copyright: The authors. This article is an open access article licensed under the terms of the Creative Commons Attributin License (http:// creativecommons.org/licenses/by/2.0) which permits unrestricted use, distribution and reproduction in any medium, provided the work is properly cited. recorded from several countries [3,4]. In India also, the parasite was considered non-pathogenic [5] for which not much attention was paid until recent record of fatal disease due to T. orientalis in crossbred adult bovines infested with Haemaphysalis bispinosa in Southern India [6].

Assam, situated in the Northeast region of India is known to have problems of tick infestation predominantly with Rhipicephalus (Boophilus) microplus [7] and prevalence of Babesia and Anaplasma in cattle [8]. There was essentially no local knowledge on the prevalence of Theileria species in the state although Theileria annulata causing bovine tropical theileriosis had been reported from neighboring states of Tripura and West Bengal $[9,10]$. In the recent past, veterinary practitioners from Assam have been experiencing a poor response to specific treatment in several 
field cases of Babesia like infections in cross-bred cattle.

A systematic study was therefore conducted using clinical, blood smear, serological, and molecular analysis in clinical outbreaks of hemoparasitic infection to address the issue, and the results are presented through this communication.

\section{Materials and Methods}

\section{Ethical approval}

The experiments comply with the guidelines laid down by the Institutional Ethical Committee and in accordance with the country law.

\section{Study area}

The study was conducted in the Southeast peri-urban area of Guwahati under Kamrup (Metropolitan) District of Assam, India. Jersey and Holstein Friesian crossbred cattle are being raised under a stall-fed unorganized farming condition in this area from which major part of milk is supplied to the city.

\section{Study population}

During May, 2012 to April, 2013, field veterinarians identified 57 clinical cases suspected to be of hemoparasitic infection on the basis of clinical symptoms such as pyrexia, anorexia, pale mucous membrane, and in severe cases jaundice. The clinical cases were attended individually for physical examination including the search for ticks on the body parts. Ticks were collected in glass vials for their identification [11-13].

\section{Hematological analysis}

The blood samples $(n=57)$ were collected in tubes with or without EDTA for parasitological, molecular, and serological studies. Giemsa stained smears prepared from superficial lymph node aspirations, and fresh blood samples were examined under a microscope for detection of parasites and in positive cases, parasitemia was estimated.

\section{Molecular study}

Genomic DNA was extracted from whole blood using DNeasy Blood and Tissue Kit (Quiagen; Catalogue No. 69504) as per manufacturer's protocol. PCR assay was carried out in a Techne-500 thermal cycler (Bibby Scientific) using established primers for Theileria annulata and T. orientalis with its variants viz. Chitose, Buffeli, and Ikeda using respective protocols for preparation of reaction mixture and thermocycling conditions [2,14] (Table-1). Additionally, established primers of Babesia bigemina, Babesia bovis, and Anaplasma marginale were also used to confirm their identity in clinical cases vis a vis differential diagnosis through molecular evaluation [15-17]. PCR products were confirmed by electrophoresis in 1.5\% agarose gel prestained with Ethidium Bromide and subsequent visualization done in gel documentation system (DNR Mini Lumi, Applied Bioimaging).

\section{Serological study}

Sera samples of all clinical cases were subjected to Plate and Dot-ELISA [18] at the Division of Parasitology, Indian Veterinary Research Institute, Izatnagar to screen for the presence of $T$. annulata antibodies.

A fully engorged adult $R(B)$. microplus tick collected from a clinical case positive to $T$. orientalis was placed for oviposition inside a dessicator at room temperature. The DNA extracted from the egg masses in triplicate were employed in PCR analysis using primers and protocols for $T$. orientalis.

Twelve cattle that were test positive for T. orientalis based on molecular diagnosis received treatment with a single injection of buparvaquone at $2.5 \mathrm{mg} / \mathrm{kg}$ body weight intramuscularly. Clinical cases of babesiosis and anaplasmosis were treated with diminazene aceturate at $3.5 \mathrm{mg} / \mathrm{kg}$ body weight intramuscularly for one occasion each and oxytetracycline at $5.0 \mathrm{mg} / \mathrm{kg}$ body weight 12 hourly intravenous for 5 days respectively. Feedback on post-treatment recovery was obtained from the field veterinarians and the cattle owners for confirmation and to exclude non-parasitic causes of hemolytic anemia.

\section{Results}

Microscopic examination of blood smears showed overall $89.47 \%$ positivity to hemoparasites. These included a large form of Babesia in 33 cases, Anaplasma in 8 cases and Theileria like organisms in 12 cases. Theileria like organisms inside the erythrocytes were small pear shaped (Figure-1), crescent (Figure-2), rod (Figure-3), dot (Figure-4), and comma-shaped (Figure-5) with trailing cytoplasm. The erythrocytic parasitemia in all positive cases was $<1 \%$. In a few cases, lymphocytes showed the presence of intracytoplasmic schizonts (Figure-6).

Polymerase chain reaction amplified 1124, $160 \mathrm{bp}$ and $776 \mathrm{bp}$ DNA fragments of B. bigemina $(\mathrm{n}=33,64.91 \%)$, A. marginale $(\mathrm{n}=8,14.03 \%)$ and T. orientalis $(\mathrm{n}=12,21.05 \%)$ (Figure-7) respectively. PCR analysis of T. orientalis positive DNA extracts using variant-specific primers, showed 3 animals positive to Ikeda variant with a product size of $826 \mathrm{bp}$ (Figure-8). T. annulata and B. bovis specific primers did not amplify the desired fragments in PCR.

Plate-ELISA and Dot-ELISA tests performed in sera of all the clinical cases using $T$. annulata antigen were all negative for homologous antibodies.

Ticks present on the bodies of animals were all identified as $R(B)$. microplus. PCR assay conducted on the DNA extracted from eggs of the tick also amplified $T$. orientalis specific primers (Figure-9).

Clinical symptoms observed in diseased cattle were fever $\left(104-106^{\circ} \mathrm{C}\right)$ with varying degrees of pale mucous membrane, anorexia, depression, dehydration, weakness, and recumbency. Dark urine and icterus were other prominent clinical signs. Animals with $T$. orientalis infection in severe cases passed tarry colored dung. 
Table-1: Standard primers used for identification of T. annulata and T. orientalis (including type chitose, buffeli, and ikeda) along with their primer sequences, amplification targets, cycling conditions, and product size.

\begin{tabular}{|c|c|c|c|c|}
\hline Parasite & Primer sequence pair & $\begin{array}{l}\text { Amplification } \\
\text { target }\end{array}$ & $\begin{array}{l}\text { Cycling } \\
\text { conditions }\end{array}$ & $\begin{array}{l}\text { Product } \\
\text { size }\end{array}$ \\
\hline T. annulata & $\begin{array}{l}\text { TaF1:5'-GTA ACC TTT AAA AAC GT-3' } \\
\text { TaR1:5'-GTT ACG AAC ATG GGT TT-3' }\end{array}$ & $\begin{array}{l}30 \text { kDa major } \\
\text { T.annulata } \\
\text { merozoite surface } \\
\text { antigen gene }\end{array}$ & $\begin{array}{l}94^{\circ} \mathrm{C}, 1 \mathrm{~min} \\
55^{\circ} \mathrm{C}, 1 \mathrm{~min} \\
72^{\circ} \mathrm{C}, 1 \mathrm{~min} \\
30 \text { cycles }\end{array}$ & $721 \mathrm{bp}$ \\
\hline T. orientalis (Entire & Tor: F1:5'-CTT TGC CTA GGA TAC TTC CT-3' & Gene encoding a & $95^{\circ} \mathrm{C}, 15 \mathrm{sec}$ & 776 bp \\
\hline T. orientalis group) & Tor: R1:5'-ACG GCA AGT GGT GAG AAC T-3' & polymorphic MPSP & $57^{\circ} \mathrm{C}, 30 \mathrm{sec}$ & \\
\hline $\begin{array}{l}\text { T. orientalis } \\
\text { (Type-Chitose) }\end{array}$ & Tor': F1:5'-GCG GAT CCT CAT CGT CTC TGC AAC T-3' & SSUrRNA gene & $\begin{array}{l}72^{\circ} \mathrm{C}, 1 \mathrm{~min} \\
30 \text { cycles }\end{array}$ & $831 \mathrm{bp}$ \\
\hline $\begin{array}{l}\text { T.orientalis } \\
\text { (Type-Buffeli) }\end{array}$ & Tor': F1:5'-GCG GAT CCG CTC TGC AAC CGC AGA G-3' & & & 825 bp \\
\hline $\begin{array}{l}\text { T.orientalis } \\
\text { (Type-Ikeda) }\end{array}$ & Tor' $:$ F1:5'-AAG GAT CCG TCT CTG CTA CCG CCG C-3' & & & 826 bp \\
\hline
\end{tabular}

T. orientalis=Theileria orientalis, $T$. annulata $=$ Theileria annulata, MPSP=Merozoite/piroplasms surface protein

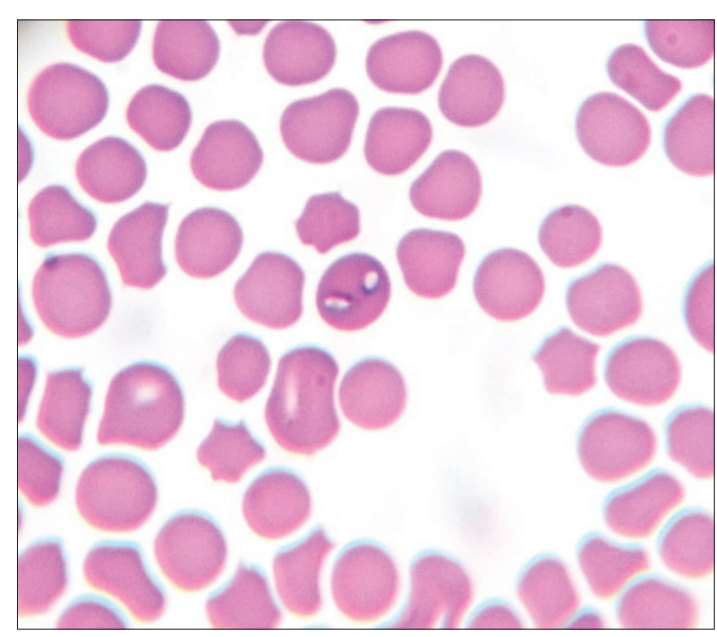

Figure-1: Giemsa stained blood smear showing paired pear-shaped red blood cell form of Theileria orientalis $(\times 1000)$.

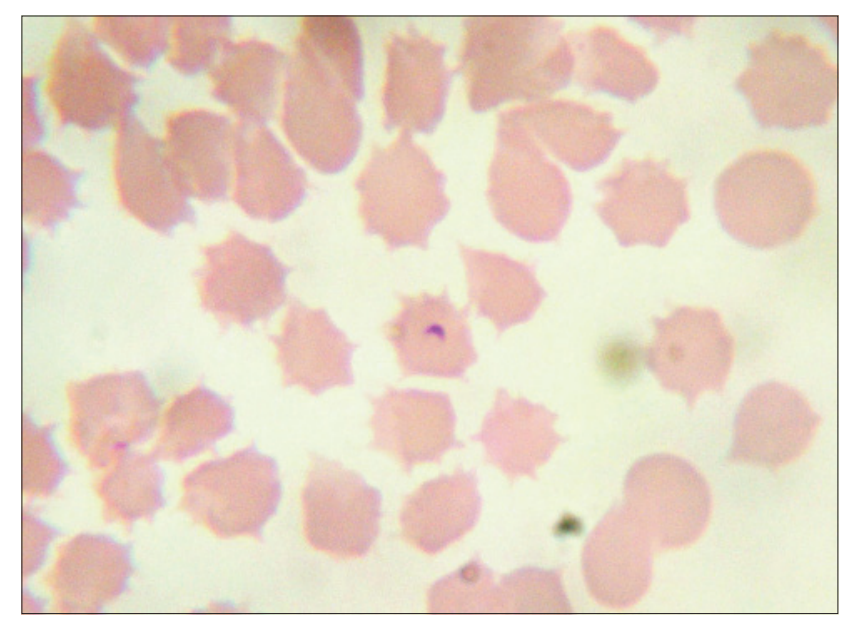

Figure-2: Giemsa stained blood smear showing crescent shaped the intraerythrocytic form of Theileria orientalis $(\times 1000)$.

Adoption of parasite-specific treatment showed gradual improvement in health with the disappearance of clinical symptoms within $48 \mathrm{~h}$ of treatment except mortality recorded in 2 animals with $T$. orientalis infection.

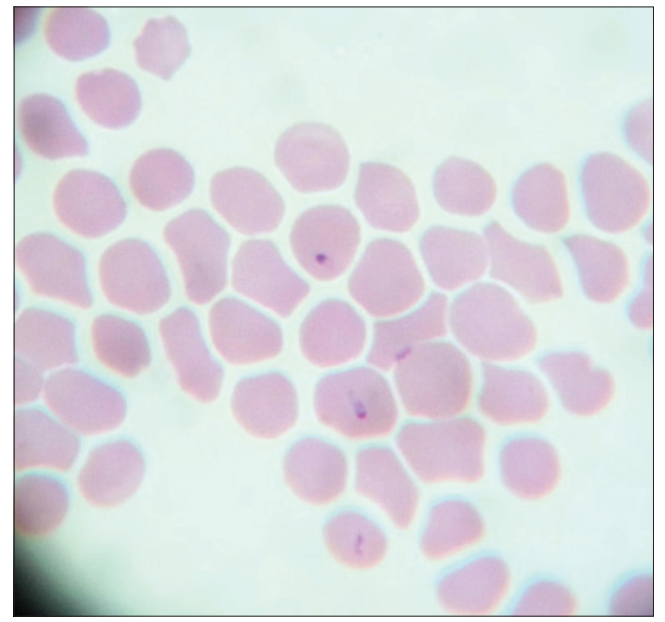

Figure-3: Giemsa stained blood smear showing the intraerythrocytic rod of Theileria orientalis $(\times 1000)$.

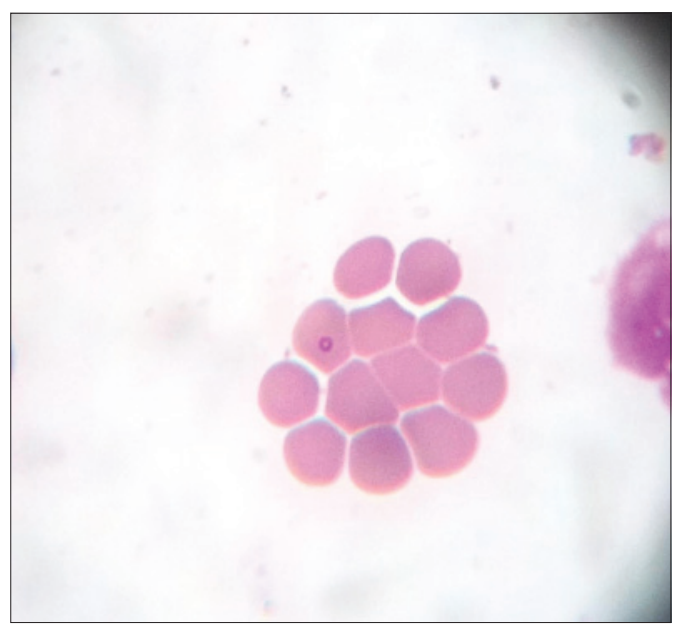

Figure-4: Giemsa stained blood smear showing dot shaped the intraerythrocytic form of Theileria orientalis $(\times 1000)$.

\section{Discussion}

Assam is situated in the central part of the Northeast India (between $24^{\circ} 8^{\prime}$ and $28^{\circ} 2^{\prime} \mathrm{N}$ latitude and $89^{\circ} 42^{\prime}$ and $96^{\circ} \mathrm{E}$ longitude). The state experiences moderately hot and very humid climate with a total annual rainfall of about $2818 \mathrm{~mm}$ favoring 


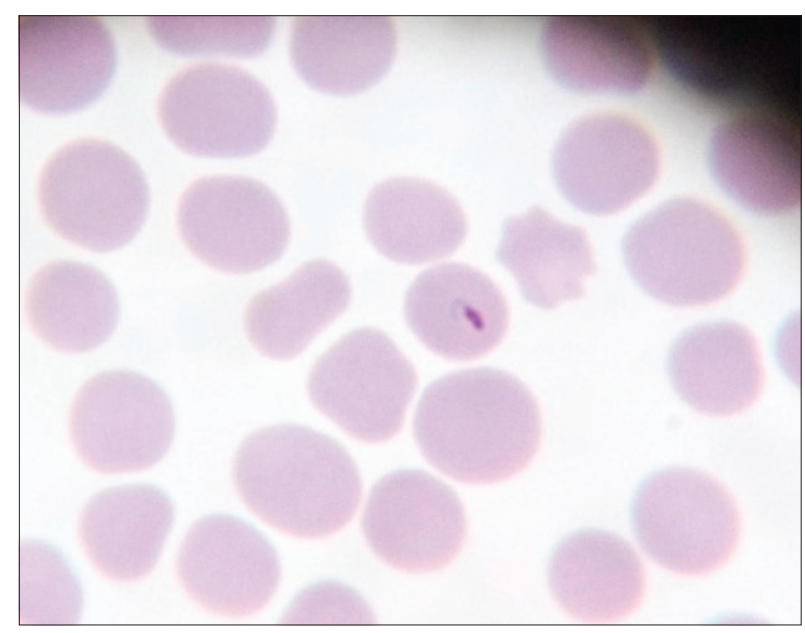

Figure-5: Giemsa stained blood smear showing comma shaped the intraerythrocytic form of Theileria orientalis $(\times 1000)$.

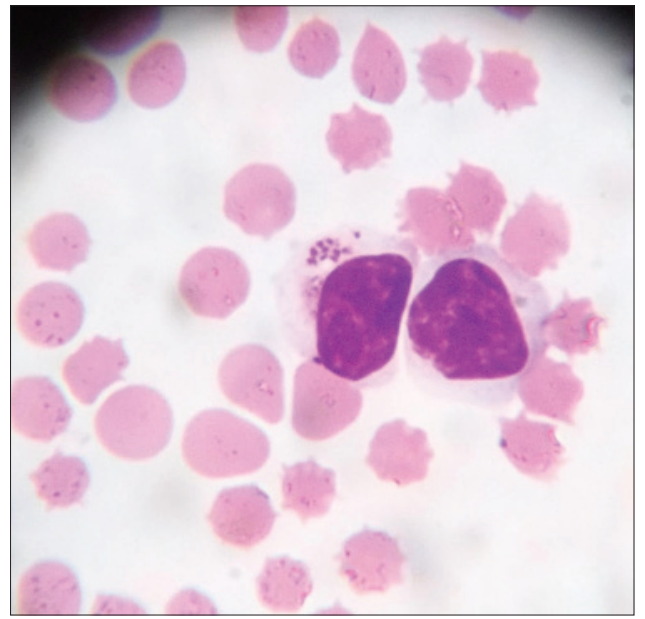

Figure-6: Giemsa stained blood smear showing intralymphocytic schizont of Theileria orientalis $(\times 1000)$.

the propagation of vectors and many vector-borne diseases of man and animals. This state is already known to be endemic for Babesia and Anaplasma of cattle [8]. Investigation of the parasitic etiology of hemolytic anemia conducted in the present study revealed the presence of erythrocytic piroplasms of Theileria like organisms [19] in blood smears and rare detection of intracytoplasmic schizont within lymphocytes. Consistent with the previous report [8], Babesia and Anaplasma were also detected in blood smears of affected cattle. Light microscopy is widely used in the most of the laboratories to gather important diagnostic informations characteristic to a particular species of hemoparasite. However, it seems to be a difficult task in field cases of natural infection to differentiate small forms of Babesia (B. bovis), Anaplasma and closely related Theileria species which have some common morphological appearances. The recent adoption of molecular techniques has made a strong impact in the field of diagnostic parasitology in supporting surveillance, monitoring and disease management programs. Molecular studies conducted in blood samples of present study confirmed the presence of T. orientalis,

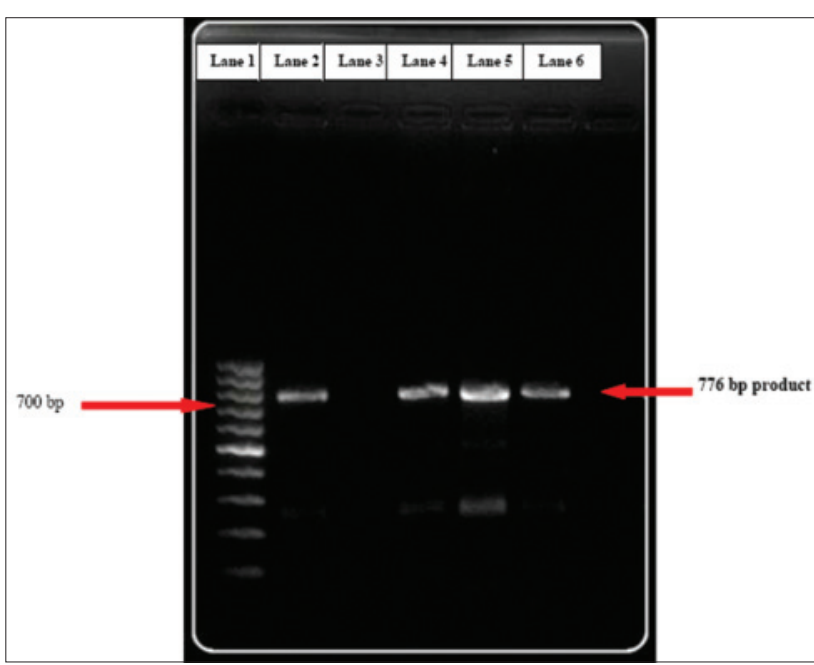

Figure-7: 776 bp fragments of $T$. orientalis DNA in 1.5\% agarose gel. (Lane 1: 100 bp DNA Marker, Lane 2: Positive control, Lane 3: Negative control, Lane 4, 5, 6: Test samples).

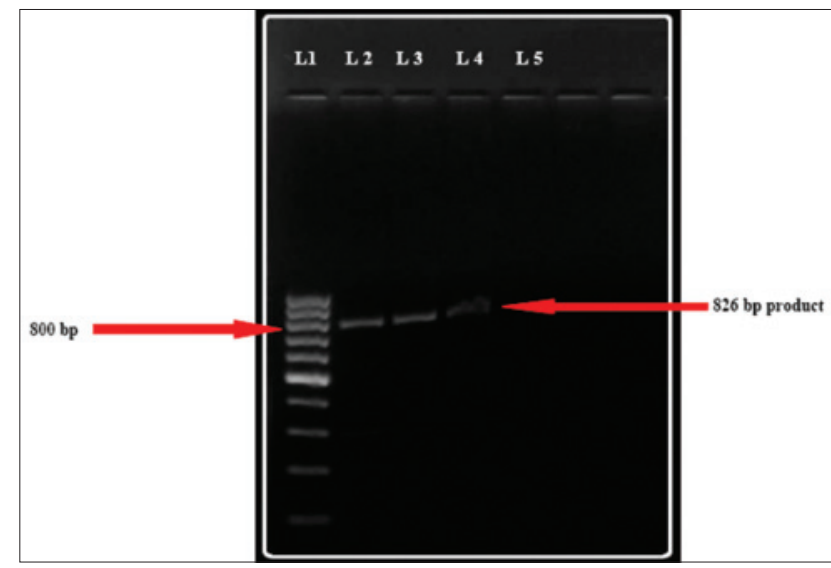

Figure-8: 826 bp fragments of Theileria orientalis (type ikeda) DNA in 1.5\% agarose gel. (Lane 1: 100 bp DNA Marker, Lane 2, 3, 4: Test Samples, Lane 5: Negative control).

$B$. bigemina, and $A$. marginale and at the same time ruled out association of $T$. annulata and B. bovis consistent with previous report made from Kerala [20]. First record of Theileria, the T. orientalis in cattle of Assam and its association with clinical outbreaks is on the line of experiences gathered by the field veterinarians who observed variable response to treatment with diminazene compounds in animals with clinical Babesia like infections. Similar reports on the prevalence of $T$. orientalis, its association with clinical outbreaks with fatal results among adult cattle have been reported recently from South India [20]. Present findings also conformed to the previous reports of T. orientalis made from other countries [2,3,21-24]. T. orientalis populations are known to consist of 8 genotypes of which involvement of Ikeda group in the production of the clinical disease have been proved by many workers $[2,4,25]$. Recent reports of Ikeda genotype of $T$. orientalis from clinical outbreaks in cattle of Australia having no history of cattle importation has also pointed out possible emergence of this variant 


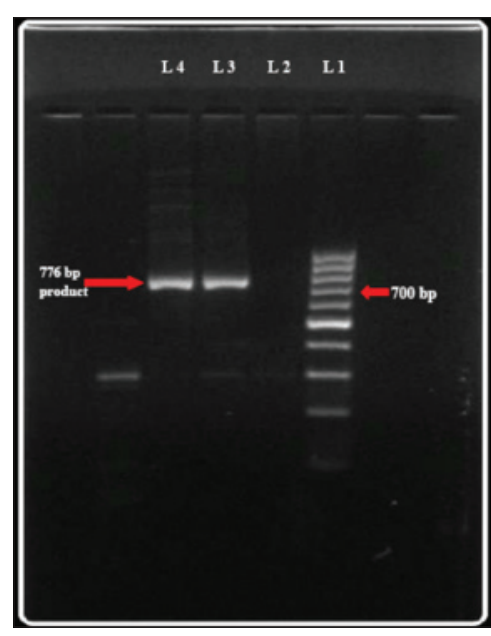

Figure-9: 776 bp fragments of Theileria orientalis DNA in Rhipicephalus (Boophilus) microplus egg in 1.5\% agarose gel. (Lane 1: 100 bp DNA Marker, Lane 2: Negative control, Lane 3: Positive control, Lane 4: Test sample).

from the existing Buffeli type through silent mutation [2] and possible existence of gene switching [26]. PCR analysis conducted further in $T$. orientalis positive blood samples in the present study using established primers of Ikeda, Buffeli, and Chitose variants showed the presence of only Ikeda genotype in 3 positive cases. This suggested the involvement of some other variants of $T$. orientalis thus warranting further confirmation and subsequent phylogenetic analysis in order to establish the different genotypes of parasite species prevalent in Assam.

Epidemiological studies conducted by several workers in different parts of India revealed a high prevalence of T. annulata [10,27]. However, PCR analysis in the present study using $T$. annulata specific primers failed to amplify parasite DNA in the blood samples. T. annulata antibody negative results obtained in the serological test conducted in sera of $T$. orientalis PCR positive cattle also confirmed the absence of T. annulata in Assam. This correlates with the previous report on the absence of Hyalomma anatolicum, the proven vector of T. annulata in cattle from Assam [7,28]. Similar situation on the absence of Hyalomma tick and T. annulata in Kerala was described [6] inspite of their prevalence record in neighboring states like Tamil Nadu and Karnataka.

PCR conducted in the DNA extracted from eggs laid by engorged $R(B)$.microplus in this study revealed presence of $T$. orientalis DNA which suggested that the tick might be the vector of $T$. orientalis infection transmitting the parasite through transovarian mode. Further investigations on tick vector are required using large sample size to authenticate the present finding. Epidemiology of T. orientalis and its vector have not been adequately studied in India. However, Haemaphysalis bispinosa was recovered from $T$. orientalis infected cattle [6] similar to reports of $H$. longicornis and other species of Haemaphysalis as a vector with transtadial transmission $[1,2]$. The reports on experimental transmission of Theileria mutans [29] and T. equi [30] by B. microplus might justify the potential of this tick to transmit $T$. orientalis under natural conditions via transovarian route. An epidemiological situation similar to the present study was also reported from Vietnam [23] where the prevalence of $T$. orientalis was on record in cattle infested with only $B$. microplus ticks.

In addition to analysis of clinical findings in T. orientalis infected cases our aim was also to obtain feedback from the practitioners on the response of animals to administration of buparvaquone which was marketed in Assam (Northeast India) soon after a diagnosis of T. orientalis infection was made. Animals in the early stage of infection showing fever, depression and inappetence responded well to treatment with buparvaquone. Consistent with previous reports [31], response to buparvaquone, as observed in the present study, was another confirmatory diagnosis to rule out non-parasitic causes of anemia which might have prevailed in animals under natural conditions. However, similar treatment provided to two Theileria positive animals in a state of recumbency and showing tarry colored dung was non-responsive and turned fatal. Although no post-mortem could be conducted in field cases, treatment failure in these 2 animals suggested severe hemorrhagic condition in the gastrointestinal tract similar to earlier record [6] of punched out ulcers in the abomasum and hemorrhagic duodenitis in cattle with $T$. orientalis fatal infection.

\section{Conclusion}

The findings of the study represent the first report on the occurrence of $T$. orientalis and involvement of pathogenic strain responsible for the clinical disease of emerging nature in Assam, India. Detection of T. orientalis DNA in the eggs of $R(B)$ microplus is another important finding that justifies the significant role of this highly prevalent vector tick species in the epidemiology of $T$. orientalis along with $B$. bigemina and A. marginale in Assam. Future studies on phylogenetic analysis and experimental tick transmission of T. orientalis in cattle should provide additional information in understanding the complete epidemiology of the parasite in the Northeast region of India including Assam.

\section{Authors' Contributions}

This study was a part of PK's MVSc dissertation under the advisory committee of PCS, KB and RKS. $\mathrm{DKS}, \mathrm{BCB}$, and $\mathrm{PB}$ provided samples from clinical cases and treatment feedback. DR and BS performed serological works at IVRI. LMB assisted in molecular works. PCS, KB, and PK drafted the manuscript with subsequent revision. All authors read and approved the final manuscript.

\section{Acknowledgments}

The research was funded by the Assam Agricultural University. The authors are thankful to 
the Dean, Faculty of Veterinary Science, Guwahati-22, Director, Indian Veterinary Research Institute, Izatnagar-243122, and Head, Division of Veterinary Parasitology, IVRI for facilities provided.

\section{Competing Interests} interests.

The authors declare that they have no competing

\section{References}

1. Fuujisaki, K. (1992) A review of the taxonomy of Theileria sergenti/buffeli/orientalis Group of parasites in cattle. $J$. Protozool. Res., 2: 87-96.

2. Kamau, J., de Vos, A.J., Playford, M., Salim, B., Kinyanjui, P. and Sugimoto, C. (2011) Emergence of new types of Theileria orientalis in Australian cattle and possible cause of theileriosis outbreaks. Parasit. Vectors., 4: 22.

3. Mc Fadden, A.M., Rawdon, T.G., Meyer, J., Makin, J., Clough, R.R., Tham, K., Mullner, P. and Geysen, D. (2011) An outbreak of haemolytic anaemia associated with infection of Theileria orientalis in naive cattle. N. Z. Vet. J., 59: 79-85.

4. Eamens, G.J., Bailey, G., Jenkins, C. and Gonsalves, J.R. (2013) Significance of Theileria orientalis types in individual affected beef herds in New South Wales based on clinical, smear and PCR findings. Vet. Parasitol., 196: 96-105.

5. Shastri, U.V., Pathak, S.V., Jadhav, K.V. and Deshpande, P.D. (1988) Occurrence of Theileria orientalis in bovines from Maharashtra state and its transmission by Haemaphysalis bispinosa ticks. Indian J. Parasitol., 12: 173-177.

6. Aparna, M., Ravindran, R., Vimalkumar, M.B., Lakshmanan, B., Rameshkumar, P., Kumar, K.G., Promod, K., Ajithkumar, S., Ravishankar, C., Devada, K., Subramanian, H., George, A.J. and Ghosh, S. (2011) Molecular characterization of Theileria orientalis causing fatal infection in crossbred adult bovines of South India. Parasitol. Int., 60: 524-529.

7. Lahkar, B.C. (1991) Studies on Ixodid ticks with special reference to Boophilus microplus (Canestrini, 1987). PhD. Thesis Submitted to Assam Agricultural University, Jorhat.

8. Singh, J., Miranpuri, G.S. and Borkakoty, M.R. (1978) Incidence of haemoprotozoa in bovines in north eastern regions of India. Indian J. Parasitol., 2: 137-138.

9. Das, S.S. (1993) Prevalence of haemoprotozoan parasites in domestic animals in Tripura (India). J. Parasitol. Appl. Anim. Biol., 2: 71-74.

10. Das, G. and Ray, D. (2003) PCR based detection of Theileria annulata infection in ticks collected from cattle of West Bengal (India). J. Vet. Parasitol., 17: 11-14.

11. Sen, S.K. and Fletcher, T.B. (1962) Veterinary Entomology and Acarology for India. ICAR, New Delhi.

12. Soulsby, E.J.L. (1982) Helminths, Arthropods and Protozoa of Domesticated Animals. $7^{\text {th }}$ ed. Bailliere Tindall, London. p809.

13. Geevarghese, G. and Mishra, A.C. (2011) Haemaphysalis ticks of India. It ed. Elsevier, London. p255.

14. D' Oliveira, C., Weide, M., Habela, M., Jacquit, P. and Jongejan, F. (1995) Detection of Theileria annulata in blood samples of carrier cattle by PCR. J. Clin. Microbiol., 10: 2665-2669.

15. Figueroa, J.V., Chives, L.P., Johnson, G.S. and Buening, G.M. (1993) Multiples polymerase chain reaction based assay for the detection of Babesia bigemina, Babesia bovis and Anaplasma marginale DNA in bovine blood. Vet. Parasitol., 50: 69-81.

16. Nutcha, P., Suporn, N., Nison, S., Patchima, I. and Sakda, D.
(2004) Specific and highly sensitive primers for PCR detection of Babesia bovis. Sci. Asia., 30: 67-73.

17. Laha, R., Das, M., Goswami, A. and Singh, P. (2012) A clinical case of babesiosis in a cross bred cow of Meghalaya. Indian J. Anim. Res., 46: 302-305.

18. Stanley, B. (2012) Development of TaSP based dot-ELISA for the diagnosis of Theileria annulata infection in cattle. MVSc. Thesis, IVRI, Bareilly, Izatnagar, U.P.

19. Stockham, S.L., Kjemtrup, A.M., Conrad, P.A., Schmidt, D.A., Robimson, T.W., Tyler, J.W., Johnson, G.C., Carson, C.A. and Cuddihee, P. (2000) Theileriosis in a Missouri beef herd caused by Theileria buffeli: A case repot, herd investigation, ultra structure, phylogenetic analysis and experimental transmission. Vet. Pathol., 37: 11-21.

20. Nair, A.S., Ravindran, R., Lakshmanan, B., Kumar, S.S., Tresamol, P.V., Saseendranath, M.R., Senthilvel, K., Rao, J.R., Tewari, A.K. and Ghosh, S. (2011) Haemoprotozoa of cattle in Northern Kerala, India. Trop. Biomed., 28: 68-75.

21. Song, K.H. and Sang, B.C. (2003) Prevalence of Theileria sergenti infection in Korean native cattle by polymerase chain reaction. Korean J. Parasitol., 41(3): 141-145.

22. Yokoyama, N., Ueno, A., Izuno, D., Kuboki, N., Khukhuu, A., Igarashi, T., Miyahara, T., Shiraishi, R., Kudo, M., Oshiro, S., Zakimi, C., Sugimoto, K. and Inokuma, H. (2010) Genotypic diversity of Theileria orientalis detected from cattle grazing in Kumamoto and Okinawa prefectures of Japan. J. Vet. Med. Sci., 73: 305-312.

23. Altangerel, K., Battsetseg, B., Battur, B., Sivakumar, T., Batmagnai, E., Javkhlan, G., Tuvshintulga, B., Igarashi, I., Matsumoto, K., Inokuma, H. and Yokoyama, N. (2011). The first epidemiological survey of Theileria orientalis infection in Mongolian cattle. Vet. Parasitol., 182: 343-348.

24. Sivakumar, T., Kothalawala, H., Abeyratne, A.E., Vimalakumar, S.C., Meewewa, A.S., Igarashia, I. and Yokoyama, N. (2012). A PCR-based survey of selected Babesia and Theileria parasites in cattle in Sri Lanka. Vet. Parasitol., 190: 263-267.

25. Perera, P.K., Gasser, R.B., Pulford, D.J.,Stevenson, M.A., Firestone, S.M., McFadden, A.M.J. and Jabbar, A. (2015) Comparison of the performance of three PCR assays for the detection and differentiation of Theileria orientalis genotypes. Parasit. Vectors., 8: 192.

26. Jenkins, C., Micallef, M., Alex, S.M., Collins, D., Djordjevic, S.P. and Bogema, D.R. (2015) Temporal dynamics and subpopulation analysis of Theileria orientalis genotypes in cattle. Infect. Genet.Evol., 32: 199-207.

27. Sahoo, B.M., Panda, M.R., Dehuri, M., Bishoi, P.C., Panda, S.K. and Mohanty, B.N. (2012) Epidemiology of haemoprotozoan infection in cattle of coastal districts of Odisha. In: Twenty Third National Congress of Veterinary Parasitology, 12-14 December, 2012, CVSc., AAU, Khanapara, Guwahati, S-I, p28.

28. Kakati, P. (2013) Studies on ticks and tick borne haemoparasitic infection of cattle in Assam. M.V.Sc. Thesis, Assam Agricultural University, Jorhat, Assam.

29. Neitz, W.O. (1956) Classification, transmission and biology of piroplasms of domestic animals. Ann. N. Y. Acad. Sci., 64: 56-111.

30. Knowles, D.P., Lowell, D.P., Kappmeyer, S., Stiller, D., Hennager, S.G. and Perryman, L.E. (1992) Antibody to a recombinant merozoite protein epitope identifies horses infected with Babesia equi. J. Clin. Microbiol., 30: 3122-3126.

31. Carter, P. (2011) Assessment of the efficacy of Buparvaquone for the treatment of 'benign' bovine theileriosis. In: Animal Health. Meat and Livestock Australia Limited, Queensland Government. 